\title{
The difficult colonoscopy
}

\author{
Todd N Witte $\mathrm{MD}^{1,2}$, Robert Enns MD ${ }^{1}$
}

C rolorectal cancer is the most common cause of cancerrelated death among nonsmokers in Canada (1) and is the second leading cause of cancer mortality overall. It is estimated that in 2007, approximately 21,000 Canadians will be diagnosed with colorectal cancer and that nearly 9000 will die from it (2). For this reason, the Canadian Task Force on Preventive Health Care recommends screening patients over the age of 50 who are at average risk for colorectal cancer (3).

Optical colonoscopy may not be a feasible initial screening test for the nation's health care budget to absorb at present; however, Canadian physicians trained in endoscopy are performing increasing numbers of colonoscopies, whether resulting from a referral after fecal occult blood testing or other screening modalities (4). In British Columbia alone, approximately 69,000 colonoscopies were performed last year (5).

\section{DEFINING 'DIFFICULT'}

Those of us performing colonoscopies are familiar with the concept that some cases are more challenging than others; however, 'difficult' is a subjective individual experience and the actual

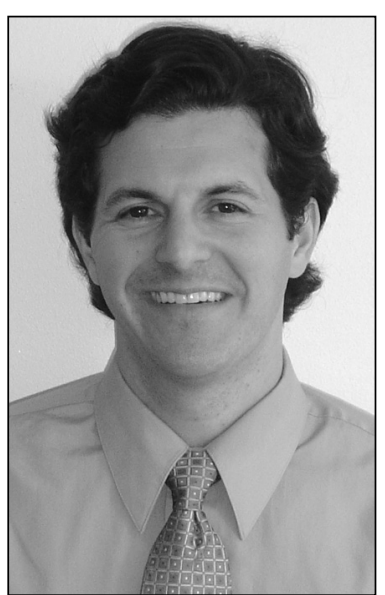

Dr Todd N Witte community of endoscopists includes a mixture of gastroenterologists, internists, surgeons and even the occasional radiologist. In a study from England (10), cecal intubation was recorded in only $76.9 \%$ of procedures, with an adjusted cecal intubation rate of only $56.9 \%$.

As in Europe, the endoscopist community in Canada is comprised of individuals with variable degrees of formal training in endoscopy, and practitioners can vary from gastroenterologists to surgeons, family doctors or internists. Based on our endoscopist community being comparable to that of Europe, we would estimate that incomplete colonoscopy rates in Canada are closer to the European data. A recently presented abstract (11) of an Ontario population-based study of nearly 6000 colonoscopies reported a completion rate of $74.2 \%$ and a recently published population-based study (12) of approximately 332,000 individuals, again from Ontario, reported that $13.1 \%$ of cases were incomplete.

\section{ISSUES AFFECTING DIFFICULTY}

There are a number of factors that affect the difficulty of the colonoscopy. Obviously, foremost definition may vary for each endoscopist. Most commonly, we speak of a 'difficult colonoscopy' being one in which it was challenging or not possible to reach the cecum. Others might be inclined to measure difficulty based on the duration of time required, or the amount of physical exertion ('endoscopist sweat') involved or even the discomfort the patient experiences. For the expert colonoscopist, a difficult colonoscopy might be one in which it is challenging to diligently examine each fold upon withdrawal. For the purposes of this discussion, we will confine ourselves to viewing the 'difficult colonoscopy' as one in which the endoscopist struggles or fails to reach the cecum.

\section{HOW BIG AN ISSUE IS THIS?}

The U.S. Multisociety Task Force on Colorectal Cancer set an overall target of $90 \%$ for cecal intubation, with a goal of $95 \%$ in cases of screening (6). In up to $10 \%$ to $20 \%$ of colonoscopies, intubation of the cecum may be considered difficult (7). Data from the United States report completion rates from gastroenterologists at academic centres ranging from $88 \%$ to $97 \%$, with community gastroenterologists reporting similar percentages (8). In a 'real life' study by Cotton et al (9) of 69 endoscopists at seven major centres, only $55 \%$ of endoscopists achieved cecal intubation rates exceeding $90 \%$, and $9 \%$ of the endoscopists had cecal intubation rates of less than $80 \%$.

Completion rates from some European studies appear to be comparatively lower. This may be because the European is the overall technical skill of the endoscopist, which includes his or her innate manual dexterity, degree of formal training and personal experience. It has recently been shown that Canadian endoscopists with higher volume performed fewer incomplete colonoscopies, whereas endoscopists in the lowest volume quintile had incompletion rates of nearly 29\%. Also quite interesting, procedures were more likely to be complete if performed in a hospital, as opposed to a community hospital or private office (12).

Loops or angulation in the colon are possibly the most common patient-related source of difficulty. Some bends require additional skill to navigate. Loops, particularly in the sigmoid colon, can result in loss of control of the endoscope as well as patient discomfort. Sometimes it is necessary to work with a loop to complete colonic intubation, and thus the adequacy of patient sedation becomes paramount. In countries where lower levels or no sedation is used, lower cecal intubation rates are not uncommon, demonstrating that at times, degree of sedation may be proportional to successful cecal intubation.

Diverticular disease also increases the degree of difficulty; because the colon with severe diverticulosis can be more spastic, it can be more difficult to achieve an adequate preparation, more difficult to insufflate and more challenging to safely find the lumen. The quality of the preparation can make a great difference in ease or difficulty of advancing the endoscope. The poorly prepped colon can be described to patients by comparing the endoscopy to driving a car on a beautiful sunny day versus

${ }^{1}$ St Paul's Hospital, University of British Columbia, Vancouver, British Columbia; ${ }^{2}$ George Washington University Hospital, Washington, DC

Correspondence: Dr Robert Enns, St Paul's Hospital, UBC, Suite \#770-1190 Hornby Street, Vancouver, British Columbia.

Telephone 604-688-6332,fax 604-689-2004, e-mail renns@interchange.ubc.ca 
driving in the middle of a snow or rain storm where one cannot easily see out the windshield.

Patients are often better prepared for a morning procedure, and thus afternoon cases can be more difficult due to poorer colon preparation. Interestingly, a recent study demonstrated that even after accounting for bowel preparation, incomplete colonoscopies were still more common in the afternoon (13), which suggests an element of operator fatigue.

The patient's body habitus also affects the degree of difficulty. It is certainly more difficult to apply counter-pressure on an obese abdomen to minimize looping. However, having a low body mass can result in an incomplete examination as well, with speculation that this is related to the paucity of visceral fat or the smaller abdominal cavity in which to fold the colon $(14,15)$. Apparently, there is a body mass index that is 'just right' for colonoscopy. Altered anatomy and adhesions from prior surgery not uncommonly complicate a colonoscopy. One frequently encountered challenge is in patients who have undergone abdominal hysterectomy, in whom colonoscopies have been demonstrated to be more technically difficult (16).

\section{SEX DIFFERENCES}

This last factor highlights the issue of sex differences contributing to colonoscopy difficulty. Several studies have confirmed that colonoscopy is more difficult to perform in women and that there are anatomic sex differences in the colons (17). The female colon is longer, with a transverse colon that is, on average, $8 \mathrm{~cm}$ longer than the male colon, and that more frequently dips into the pelvis. The female colon is therefore more likely to be acutely angulated and tortuous. There is also a greater potential for angulation as the colon emerges from the pelvis, over the uterus and into the left lower quadrant. In a study (18) using magnetic threedimensional imaging, it was shown that looping does occurs more frequently in women.

\section{WHAT YOU CAN DO WITHOUT SPECIAL EQUIPMENT}

Experienced endoscopists have learned 'tricks' to increase their cecal intubation rates. While insufflation is important on withdrawal to examine the folds of the colon, excess air on insertion can cause additional looping because the expanded colon causes sharper angulation. Therefore, one tactic is to either limit the air used on intubation, or to suction air when encountering difficult angulation. Similarly, changing the position of the patient will often change the anatomy of the colon to permit passage beyond an otherwise challenging angle. It is reasonable to do a full turn of the patient from left lateral, to back, to right lateral, to prone before aborting a colonoscopy.

It is important for the endoscopist to pay attention to loops and to minimize their formation by telescoping the bowel over the endoscope via the technique of reduction. When too much loop has been left in the colon and the cecum cannot be reached, the solution is sometimes to withdraw the endoscope, take out the troublesome loop, and reintubate the colon with great care to avoid loop formation. Counter pressure can often be helpful in such a scenario.

In some cases, particularly in women, many endoscopists find that use of a thinner endoscope, such as a pediatric colonoscope, can be advantageous. This endoscope is particularly helpful for navigating the female sigmoid colon; however, the endoscope's 'floppiness' can sometimes become a hindrance toward the end of the procedure when trying to navigate those final centimeters to the cecum. Some endoscopes have a variable stiffness mechanism that is useful in cases where a more rigid endoscope is needed. When this is not available, some endoscopists achieve a similar increased stiffness by placing a biopsy forcep down the endoscope, then opening and applying tension on it.

When presented with a difficult colonoscopy, some endoscopists will use fluoroscopy to obtain a radiographic image of the endoscope in the colon and use this to determine where and what the problem is. In some cases, navigating the flexures can be the cause of difficulty. The endoscopist can ask the patient to change position if he or she is not overly sedated, with movement from the left lateral to the supine position often being very helpful for navigating the hepatic flexure. Similarly, having the patient take a deep breath will cause the diaphragm to lower and may help the endoscope make the turn at a flexure.

Similar to knowing when to fold one's cards in a game of poker, on some days, some colons are just not meant to be intubated completely. This is particularly so in cases of poor preparation. Evaluating the reason for the poor preparation is critical. If the case took place in the afternoon, it may be better to reschedule the patient for a morning procedure or to do a split-dose prep with one-half of the solution given the evening before, and one-half given the morning of the procedure (19). The morning procedure also has the advantage of lower operator fatigue.

Finally, it is important to be honest with oneself. Is this too difficult a colonoscopy for your level of training and skill level? Should you refer the patient to another endoscopist who might have an easier time completing the procedure? Should you refer the patient to a different centre, where perhaps specialized equipment is available?

\section{SPECIAL EQUIPMENT}

One of the joys of gastroenterology is the continuous array of new devices, many of which are being specifically designed to assist with managing the more challenging colonoscopy. One solution to the problem is to redesign the colonoscope completely, which has been illustrated by Neoguide (Neoguide Systems, USA). In contrast to the conventional endoscope, where only the tip of the endoscope can be manoeuvred, the Neoguide contains articulated computer-controlled segments throughout the length of the endoscope. A sensor is placed at the anus, and the computer system constructs a three-dimensional map of the path of the endoscope and ensures that each segment of the endoscope follows the path taken by the tip of the endoscope in a 'follow the leader' fashion (20). It is suggested that this device will result in comparatively less looping, a more comfortable colonoscopy (possibly without sedation) and a higher rate of completed colonoscopies (21). This device is FDA approved; however, publication of human trials is still pending.

The Aer-O-Scope (GI View, Ltd, Israel) is another attempt to redesign the colonoscope. This product aims to be a disposable, self-navigating, self-propelled device with a 360 degree view (front, rear and side of the endoscope) of the colonic mucosa. The colonoscope consists of an optical capsule embedded in the front of a lightweight balloon attached to a supply cable. A rectal balloon is inserted distally, and the optical 
balloon glides through the colon via carbon dioxide propulsion by filling the space between the rectal balloon and itself. Images are viewed live on a personal computer during intubation and withdrawal, and can also be played back. The current model only has diagnostic potential; however, the company is working on developing the next model with biopsy and polypectomy capabilities. It is currently an investigational device only (22).

Double balloon endoscopy (DBE) is a fairly new technique, used largely to examine the small bowel. The Fujinon DBE endoscope (Fujinon, Inc, USA) consists of a $200 \mathrm{~cm}$ enteroscope and a $140 \mathrm{~cm}$ overtube, each of which has an inflatable balloon on the end. When inflated, the balloons can be used to anchor the bowel, allowing the endoscope to be gradually navigated further. Antegrade DBE resembles a sophisticated push enteroscopy. Retrograde DBE is performed to complete the evaluation of the small bowel from terminal ileum proximally. While not designed for this purpose, the DBE endoscope has been reported to be highly effective for accomplishing a complete colonoscopy when conventional colonoscopy has failed (23). Olympus has recently begun marketing a single balloon endoscope (Olympus, USA), again intended for the small bowel, which may similarly prove useful in the difficult colonoscopy.

Wireless capsule endoscopy is another recent technology intended initially for imaging the small bowel. The PillCam (Given Imaging, Israel) is an $11 \mathrm{~mm} \times 26 \mathrm{~mm}$ capsule containing a battery-powered camera that tumbles through the small bowel taking nearly 60,000 pictures that are later analyzed using a platform run from a personal computer. When performing this study for its usual small bowel indication, images of the colon are typically inadequate for evaluation because the video and battery duration ( $8 \mathrm{~h}$ ) usually ends shortly after entering the colon. Also, the views and lighting are inadequate for comment on the colon, a problem exacerbated by the typically poor colon preparation. Modifications have been made to the original PillCam to permit better visualization of the esophagus (eg, PillCam ESO), and similarly, Given Imaging is developing a PillCam COLON (24), which may be useful for screening the left colon in incomplete colonoscopies.

Shapelock (USGI Medical, USA) is a highly sophisticated metal overtube that is flexible when initially inserted into the gastrointestinal tract and can be made rigid when desired. Use of this product in a tortuous sigmoid colon is intended to enable passage of a colonoscope through the rigid overtube without encountering sigmoid looping (25).

Realizing the idiosyncrasies of the female sigmoid colon, Olympus has designed a prototype variable stiffness colonoscope that tapers from the adult diameter to the pediatric diameter of $11.3 \mathrm{~mm}$ at $25 \mathrm{~cm}$ (26). This device is intended to be a compromise between the adult colonoscope and the thinner pediatric colonoscope often helpful in female colons.

A final new device for improving colonoscopy success is a mucosectomy cap. A group from Hong Kong described their positive experience with 'cap-assisted colonoscopy' on previously incomplete colonoscopies (27). This is possibly the least expensive of all the aforementioned specialized devices, and may be readily available in endoscopy suites where endoscopic mucosal resection is also performed. Admittedly, there is limited experience with this method.

\section{CONCLUSION}

Although large-scale, prospective randomized trials of screening colonoscopy have not been performed, cohort studies have demonstrated reduced incidence of colon cancer by endoscopic removal of adenomatous polyps (28). If colonoscopy is to be the true 'gold standard' for prevention of colon cancer, the complete visualization and removal of abnormal tissue must be ensured. This begins with meeting, or ideally exceeding, the set goals of $90 \%$ to $95 \%$ cecal intubation. No two colons are alike and some may be inherently more difficult to completely intubate. Endoscopic skill is required and 'tricks' are often helpful. Emerging technologies will additionally help with difficult cases and enable the endoscopist to handle even the most challenging 'colons' with relative ease.

\section{REFERENCES}

1. Schabas RE. Colorectal cancer screening in Canada: It's time to act. CMAJ 2003;168:178-9.

2. Canadian Cancer Society. Colorectal cancer stats. $<$ www.cancer.ca> (version current at June 27, 2007).

3. Canadian Task Force on Preventive Health Care. Colorectal cancer screening: Recommendation statement from the Canadian Task Force on Preventive Health Care. CMAJ 2001;165:206-8.

4. Shapero TF, Hoover J, Paszat LF, et al. Colorectal cancer screening with nurse-performed flexible sigmoidoscopy: Results from a Canadian community-based program. Gastrointest Endosc 2007;65:640-5

5. Gray J. Presidential address. The annual meeting of the BC Society of Gastroenterologists. Vancouver, British Columbia, June 16, 2007.

6. Rex DK, Bond JH, Winawer S, et al. Quality in the technical performance of colonoscopy and the continuous quality improvement process for colonoscopy: Recommendations of the U.S. Multi-Society Task Force on Colorectal Cancer. Am J Gastroenterol 2002;97:1296-308.

7. Hawari R, Pasricha PJ. Going for the loop: A unique overtube for the difficult colonoscopy. J Clin Gastroenterol 2007;41:138-40.

8. Rathgaber SW, Wick TM. Colonoscopy completion and complication rates in a community gastroenterology practice. Gastrointest Endosc 2006;64:556-62.

9. Cotton PB, Connor P, McGee D, et al. Colonoscopy: Practice variation among 69 hospital-based endoscopists. Gastrointest Endosc 2003;57:352-7.

10. Bowles CJ, Leicester R, Romaya C, Swarbrick E, Williams CB, Epstein O. A prospective study of colonoscopy practice in the UK today: Are we adequately prepared for national colorectal cancer screening tomorrow? Gut 2004;53:277-83.

11. Baxter NN, Goldwasser MA, Paszat L, Saskin R, Urbach DR, Rabeneck L. A population-based case control study of the effectiveness of colonoscopy for prevention of death from CRC. Gastroenterology 2007;132:A-88.

12. Shah H, Paszat LF, Saskin R, Stukel TA, Rabeneck L. Factors associated with incomplete colonoscopy: A population-based study. Gastroenterology 2007;132:2297-303.

13. Sanaka MR, Shah N, Mullen KD, Ferguson DR, Thomas C, McCullough AJ. Afternoon colonoscopies have higher failure rates than morning colonoscopies. Am J Gastroenterol 2006;101:2726-30.

14. Anderson JC, Gonzalez JD, Messina CR, Pollack BJ. Factors that predict incomplete colonoscopy: Thinner is not always better. Am J Gastroenterol 2000;95:2784-7.

15. Waye JD. Completing colonoscopy. Am J Gastroenterol 2000;95:2681-2.

16. Cirocco WC, Rusin LC. Factors that predict incomplete colonoscopy. Dis Colon Rectum 1995;38:964-8.

17. Streett SE. Endoscopic colorectal cancer screening in women Can we do better? Gastrointest Endosc 2007;65:1047-9.

18. Rowland RS, Bell GD, Dogramadzi S, Allen C. Colonoscopy aided by magnetic 3D imaging: Is the technique sufficiently sensitive to detect differences between men and women? Med Biol Eng Comput 1999;37:673-9.

19. Rostom A, Jolicoeur E, Dubé C, et al. A randomized prospective trial comparing different regimens of oral sodium phosphate and 
polyethylene glycol-based lavage solution in the preparation of patients for colonoscopy. Gastrointest Endosc 2006;64:544-52.

20. NeoGuide Systems. NeoGuide technology. <www.neoguidesystems.com/technology.html> (Version current at June 27, 2007)

21. Eickhoff A, Jakobs R, Kamal A, Mermash S, Riemann JF, van Dam J. In vitro evaluation of forces exerted by a new computer-assisted colonoscope (the NeoGuide Endoscopy System). Endoscopy 2006;38:1224-9.

22. A new era in colonoscopy. <www.giview.com/> (Version current at June 27, 2007)

23. Pasha SF, Harrison ME, Das A, Corrado CM, Arnell KN, Leighton JA. Utility of double-balloon colonoscopy for completion of colon examination after incomplete colonoscopy with conventional colonoscope. Gastrointest Endosc 2007;65:848-53.

24. Eliakim R, Fireman Z, Gralnek IM, et al. Evaluation of the PillCam colon capsule in the detection of colonic pathology: Results of the first multicenter, prospective, comparative study. Endoscopy 2006;38:963-70.

25. Raju GS, Rex DK, Kozarek RA, Ahmed I, Brining D, Pasricha PJ. A novel shape-locking guide for prevention of sigmoid looping during colonoscopy. Gastrointest Endosc 2004;59:416-9.

26 Anderson JC, Walker G, Birk JW, Alpern Z, Von Althen I. Tapered colonoscope performs better than the pediatric colonoscope in female patients: A direct comparison through tandem colonoscopy. Gastrointest Endosc 2007;65:1042-7.

27. Lee YT, Hui AJ, Wong VW, Hung LC, Sung JJ. Improved colonoscopy success rate with a distally attached mucosectomy cap. Endoscopy 2006;38:739-42.

28. Winawer SJ, Zauber AG, Ho MN, et al. Prevention of colorectal cancer by colonoscopic polypectomy: The National Polyp Study Workgroup. N Engl J Med 1993;329:1977-81. 


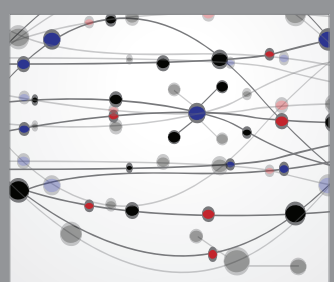

The Scientific World Journal
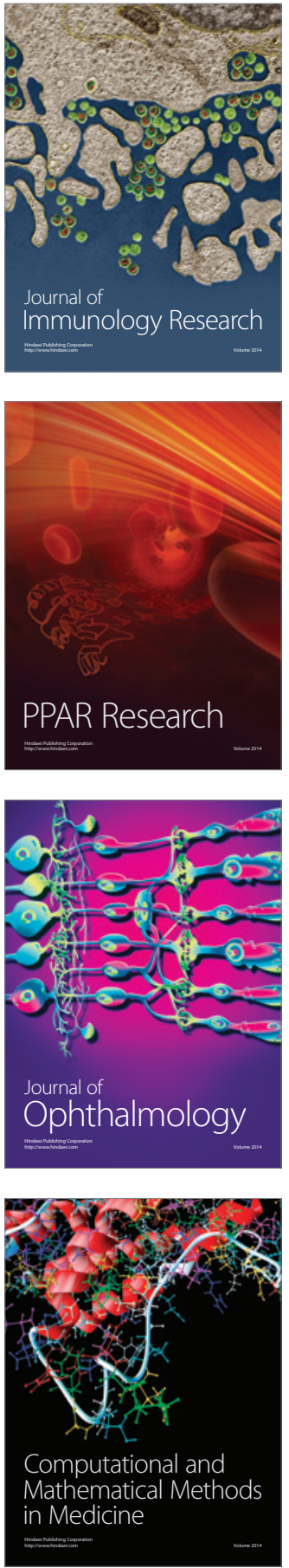

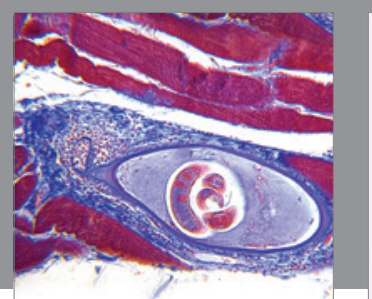

Gastroenterology Research and Practice

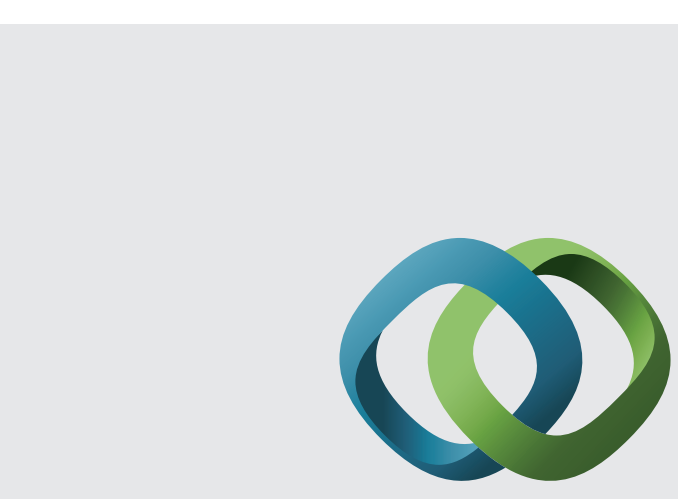

\section{Hindawi}

Submit your manuscripts at

http://www.hindawi.com
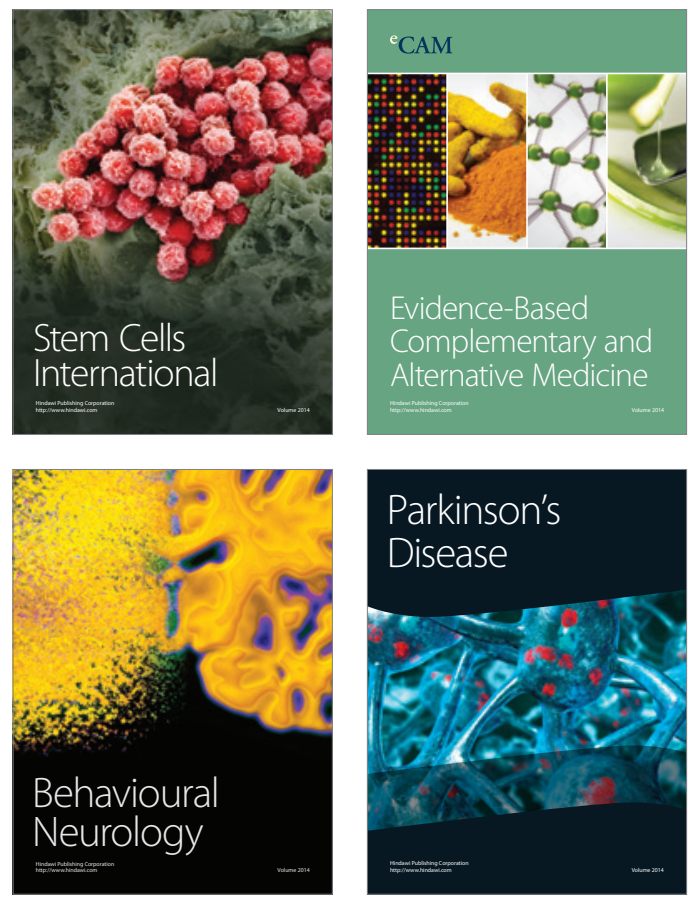
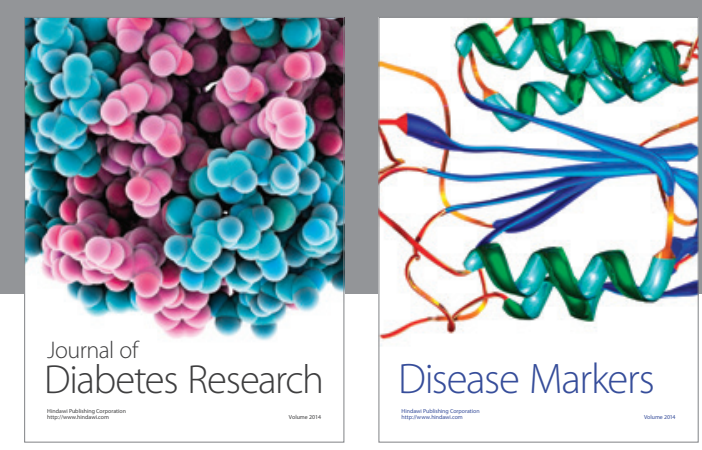

Disease Markers
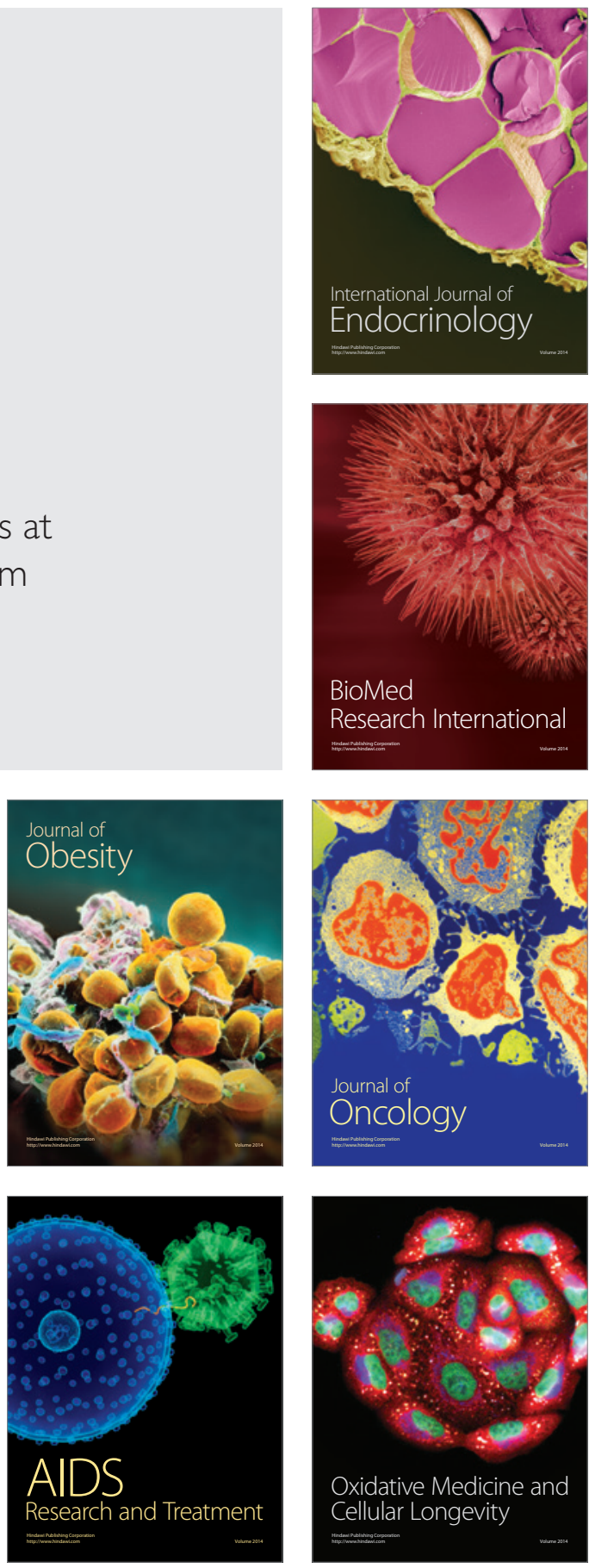